\title{
Influence of genotype on the modulation of gene and protein expression by n-3 LC-PUFA in rats
}

\author{
Elisa Boschetti • Mattia Di Nunzio • \\ Francesca Danesi • Vitaliano Tugnoli • \\ Alessandra Bordoni
}

Received: 22 November 2012/ Accepted: 22 May 2013/Published online: 7 June 2013

(C) Springer-Verlag Berlin Heidelberg 2013

\begin{abstract}
It is becoming increasingly apparent that responsiveness to dietary fat composition is heterogeneous and dependent on the genetic make-up of the individual. The aim of this study was to evidence a genotype-related differential effect of n-3 long-chain polyunsaturated fatty acids (n-3 LC-PUFA) on the modulation of hepatic genes involved in cholesterol metabolism. Fourteen spontaneously hypertensive $(\mathrm{SH})$ rats, which present a naturally occurring variation in the gene encoding for sterol responsive element binding protein 1 (SREBP-1), contributing to their inherited variation in lipid metabolism, and 14 Wistar-Kyoto (WK) rats were fed a control diet or an n-3 LC-PUFA enriched diet for 90 days. Plasma lipid profile, total lipid fatty acid composition in plasma and liver, and the expression of SREBP-1 and 2, 3-hydroxy-3methyl-glutaryl-CoA reductase, low-density lipoprotein receptor, and acyl-CoA:cholesterol acyltransferase 2 encoding genes and proteins were determined. The positive effect of the enriched diet on the serum lipid profile, particularly on total cholesterol and triglyceride level, was clearly evidenced in both WK and SH rats, but n-3 LCPUFA acted through a different modulation of gene and
\end{abstract}

E. Boschetti · V. Tugnoli

Department of Biomedical and Neuromotor Science, University

of Bologna, via Belmeloro 8/2, 40126 Bologna, BO, Italy

\section{Di Nunzio}

Interdepartmental Centre for Industrial Agri-Food Research,

University of Bologna, piazza Goidanich, 60,

47521 Cesena, FC, Italy

F. Danesi · A. Bordoni $(\bowtie)$

Department of Agri-Food Sciences and Technologies,

University of Bologna, Campus di Scienze degli Alimenti,

piazza Goidanich, 60, 47521 Cesena, FC, Italy

e-mail: alessandra.bordoni@unibo.it protein expression that appeared related to the genetic background. Our study evidences a different transcriptional effect of specific nutrients related to genetic variants.

Keywords n-3 LC-PUFA - Gene expression · Protein expression - Genotype · Cholesterol - Spontaneously hypertensive rats

$\begin{array}{ll}\text { Abbreviations } & \\ \text { AA } & \text { Arachidonic acid } \\ \text { ACAT-2 } & \text { Acyl-CoA:cholesterol acyltransferase 2 } \\ \text { AI } & \text { Atherogenic index } \\ \text { ALA } & \alpha \text {-Linolenic acid } \\ \text { CI } & \text { Confidence interval } \\ \text { CVD } & \text { Cardiovascular disease } \\ \text { DHA } & \text { Docosahexaenoic acid } \\ \text { EPA } & \text { Eicosapentaenoic acid } \\ \text { FA } & \text { Fatty acid } \\ \text { GAPDH } & \text { Glyceraldehyde-3-phosphate- } \\ \text { HDL-C } & \text { dehydrogenase } \\ \text { HMGCR } & \text { High-density lipoprotein cholesterol } \\ \text { HNF1 } \alpha & \text { reductase } \\ \text { LA } & \text { Hepatocyte nuclear factor 1 } \alpha \\ \text { LDL-C } & \text { Linoleic acid } \\ \text { LDLR } & \text { Low-density lipoprotein cholesterol } \\ \text { n-3 LC-PUFA } & \text { Low-density lipoprotein receptor } \\ \text { LXR } & \text { n-3 long-chain polyunsaturated fatty acid } \\ \text { n.s. } & \text { Sterol-responsive liver X receptor } \\ \text { PCSK9 } & \text { Not significant } \\ \text { qPCR } & \text { Proprotein convertase subtilisin/kexin } \\ \text { SDS-PAGE } & \text { type-9 } \\ & \text { Quantitative PCR } \\ & \text { gel electrophoresis } \\ & \end{array}$




$\begin{array}{ll}\text { SH } & \text { Spontaneously hypertensive } \\ \text { Srebf } & \begin{array}{l}\text { Sterol regulatory element binding } \\ \text { transcription factor }\end{array} \\ \text { SREBP } & \text { Sterol responsive element binding protein } \\ \text { St } & \text { Standard } \\ \text { TBST } & \text { Tris-buffered saline tween-20 } \\ \text { TG } & \text { Triglyceride } \\ \text { TOT-C } & \text { Total cholesterol } \\ \text { WB } & \text { Western blotting } \\ \text { WK } & \text { Wistar-Kyoto }\end{array}$

\section{Introduction}

n-3 long-chain polyunsaturated fatty acid (n-3 LC-PUFA) dietary intake and tissue content are closely related to numerous health outcomes including cardiovascular disease morbidity and mortality (Leaf 2006), immunological and inflammatory responses (Trak-Fellermeier et al. 2004; Kompauer et al. 2005), and mental health and psychiatric disorders (Muskiet and Kemperman 2006).

The response to eicosapentaenoic acid (EPA) + docosahexaenoic acid (DHA) intervention is highly heterogeneous and supposed to be related to genetic variations; evidence existing on whether the effects of $n-3$ PUFA on health can be modulated by genetic variation in humans has been recently reviewed by Corella and Ordovás (2012) and Madden et al. (2011). Despite the fact that multiple observational studies have shown statistically significant interactions between n-3 PUFA and certain genetic variants, particularly related to the desaturase and the peroxisome proliferator-activated receptor- $\alpha$ encoding genes, firm conclusions cannot be established from intervention studies. To date, the most of the intervention studies were not basically designed to investigate the effect of a genetic variant or previously selected genetic variants, but to first undertake the intervention and then genotype the individuals. To do a priori, the choice of the main genetic variants to be studied and select individuals for their genotype could improve our knowledge on genotype influence on n-3 LCPUFA effects.

The aim of this study was to verify whether the response to an n-3 LC-PUFA supplementation is different in spontaneously hypertensive (SH) and in Wistar-Kyoto (WK) rats, considered as SH control strain (Okamoto and Aoki 1963). Both SH and WK were inbred strains; since each inbred strain has a unique genotype, all individuals in each group were isogenic (genetically identical). Although every genetic component that plays a role in the development of systemic hypertension has not been identified, the main characteristics of $\mathrm{SH}$ rat genotype have been already reported in details (Greenhouse et al. 1990; Johnson et al. 1992). Among them, the variation in the sterol regulatory binding protein 1 (SREBP-1) encoding gene (Srebf-1) could contribute to the inherited variation in lipid metabolism observed in SH rats.

The SREBP family consists of the isoforms (SREBP-1 and SREBP-2) that are encoded by two different genes (Srebf-1 and Srebf-2) (Shimomura et al. 1997). In contrast to SREBP-2, SREBP-1 is transcribed into two splice variants (Yokoyama et al. 1993): SREBP-1a, controlling cholesterol and lipid synthesis, and SREBP-1c, solely regulating the synthesis of fatty acids (Horton et al. 2003; Raghow et al. 2008). The relative activities of the two SREBP-1 isoforms differ: SREBP-1a is a potent activator of all SREBP-responsive genes, owing to its long transactivation domain encoded by its first exon, while in SREBP-1c, this exon encodes a shorter transactivation domain that is less potent than SREBP-1a (Horton et al. 2002). SH rats carry a valine to methionine substitution in the $\mathrm{COOH}$ terminal regulatory domain of SREBP-1; since SREBP-1a and SREBP-1c are derived from a different splicing of the same gene, with a nearly identical $\mathrm{COOH}$ terminal domain, the substitution is expected to be present in both isoforms (Pravenec et al. 2001).

When expressed at physiologic levels, the nuclear forms of all three SREBPs activate genes encoding multiple enzymes in the cholesterol and fatty acid biosynthetic pathways as well as the low-density lipoprotein receptor (LDLR) (Horton et al. 2003). Pravenec et al. (2008) evidenced that the variant Srebf-1 form carried by SH rats underlies a quantitative trait locus influencing hepatic cholesterol levels in response to a high cholesterol diet, in agreement with the results of association studies indicating that common polymorphisms affecting SREBP-1 may influence cholesterol synthesis in humans (Laaksonen et al. 2006).

At present, no data are reported in the literature about a possible differential response to n-3 LC-PUFA due to $\mathrm{SH}$ genotype. In the present study, WK and SH rats were fed a standard diet or a diet supplemented with n-3 LC-PUFA, EPA (20:5 n-3) and DHA (22:6n-3). At the end of the dietary treatment, the plasma lipid profile and the plasma and liver total lipid fatty acid composition were determined. Furthermore, since the modulation of gene transcription is one of the n-3 LC-PUFA main mechanisms of actions (Bordoni et al. 2007), the expressions of some genes as well of the corresponding encoded proteins were determined in the liver. We focused on genes encoding for SREBP-1 and SREBP-2 since the reported genetic variation of Srebf-1 could interfere with the cholesterol-lowering effect of n-3-LC-PUFA, and on genes encoding for hydroxymethyl-glutaryl-coenzyme A reductase (HMGCR), LDLR, and acyl-CoA:cholesterol acyltransferase 2 
(ACAT-2) since they have a central role in cholesterol metabolism and trafficking, and their transcriptional regulation is mediated by SREBP.

\section{Materials and methods}

\section{Materials}

Diets were from Mucedola (Milan, Italy). Chloroform, n-hexane, sodium chloride and Tris (hydroxymethyl) aminomethane were from Carlo Erba reagenti (Milan, Italy). Methanol, potassium chloride, sodium sulphate anhydrous, Tris-borate EDTA buffer, methanolic-HCl, Triton X-100, glycine, $\mathrm{N}, \mathrm{N}, \mathrm{N}^{\prime}, \mathrm{N}^{\prime}$-tetramethylethylenediamine, primary antibody anti-actin and secondary antibody anti-mouse were purchased from Sigma Chemical Co. (Milan, Italy). DNA Ladder, SYBR Safe DNA gel stain and Ultrapure Agarose were from Invitrogen (Paisley, UK). $40 \%$ acrylamide/bis solution, ammonium persulfate, blotting-grade milk and sodium dodecyl sulphate (SDS) were from Bio-Rad Laboratories (Hercules, CA, USA). Premade primers QuantiTect Primer Assay 200 (Srebf-1, QT00432684; Srebf-2, QT00403305; Acat-2, QT00412461; Ldlr, QT00177744; Hmgcr, QT00182861; Gapdh, QT00199633) were from Qiagen (Hamburg, Germany). $\beta$-Actin was a custom primer purchased from Integrated DNA Technologies (Leuven, Belgium). Primary antibodies anti SREBP-1 (ab3259), SREBP-2 (ab30682), LDLR (ab30532), HMGCR (ab98018), ACAT-2 (ab123934) and Goat pAb secondary Ab to Rabbit IgG (ab6721) were from AbCam (Cambridge, UK).

\section{Methods}

\section{Animals and diet}

The n-3 LC-PUFA solution used for diet preparation contained EPA and DHA as ethyl esters, in the ratio 0.9:1.5, and was added in appropriate amount $(0.1 \% \mathrm{w} / \mathrm{w})$ to the standard diet during its preparation. Protein (about $21 \mathrm{~g} /$ $100 \mathrm{~g}$ ), lipid (about $8 \mathrm{~g} / 100 \mathrm{~g}$ ) and carbohydrate content (about $61.5 \mathrm{~g} / 100 \mathrm{~g}$ ) was in the normal range of adequacy for rats in the standard diet, which contained appropriate amounts of vitamins and minerals.

Fourteen male WK and 14 male SH rats aged 14 weeks were used. Animals were housed in individual cages under strictly controlled condition of temperature $\left(20 \pm 2{ }^{\circ} \mathrm{C}\right)$ and humidity (60-70\%) with a 12-h dark-light cycle and were weighted each week. Water and food were provided ad libitum, and food consumption was registered daily. After 15 days of standard (St) diet, both WK and SH rats were randomly divided into two subgroups, one kept at the standard diet (WK-St and SH-St) and the other fed the n-3
LC-PUFA supplemented diet (WK-PUFA and SH-PUFA). The dietary treatment lasted 3 months; then, after an $8 \mathrm{~h}$ fasting, rats were weighted, anesthetized and killed. Blood samples were collected in heparinized test tubes, and livers were quickly excised and frozen at $-80^{\circ} \mathrm{C}$ in RNALater (Ambion Inc., Austin, TX, USA). Plasma was obtained by centrifugation at $800 \mathrm{~g}$ for $5 \mathrm{~min}$, and stored at $-20{ }^{\circ} \mathrm{C}$ until analysis.

The Animal Care Committee of the University of Bologna approved the study (Prot. 49264-X/6).

\section{Lipid profile and fatty acid (FA) composition}

Plasma lipid profile was evaluated using commercial kits (Roche Diagnostics SpA, Milan, Italy) according to the manufacturer's instruction and determined spectrophotometrically using a Hitachi 911 auto analyser. LDL cholesterol (LDL-C) level and the atherogenic index (AI) were estimated indirectly using the following formulas:

LDL-C $=$ TOT-C $-[$ HDL-C $+($ TG/5) $]$

(Friedewald etal. 1972)

$\mathrm{AI}=($ TOT-C - HDL-C $) /$ HDL-C $\quad($ Choi et al. 1991)

where HDL-C: high-density lipoprotein cholesterol, TG: triglyceride, and TOT-C: total cholesterol.

Total lipid FA composition was determined in plasma and liver by gas chromatographic analysis. Lipids were extracted from $300 \mu \mathrm{l}$ plasma or $0.3 \mathrm{~g}$ hepatic tissue according to Folch et al. (1957), and methyl esterified according to Stoffel et al. (1959). Methyl esters dissolved in n-hexane were gas chromatographed on a Carlo Erba model 4160 (Milan, Italy) equipped with a capillary column (30 $\mathrm{m} \times 0.25 \mathrm{~mm}$ i.d.) filled with a thermo stable stationary phase (SP 2340, 0.10-0.15 $\mu \mathrm{m}$ film thickness), at a programmed temperature $\left(160-210{ }^{\circ} \mathrm{C}\right.$, with a $8{ }^{\circ} \mathrm{C} /$ min gradient), with $\mathrm{He}$ as carrier gas at a flow rate of $2 \mathrm{ml} /$ min as previously reported (Righi et al. 2011). Gas chromatographic traces and quantitative evaluations were obtained using a Chrom Card Software (Thermo Electron Scientific, Milan, Italy) computing integrator.

RNA extraction, reverse transcription and gene expression analysis

Thirty micrograms of hepatic tissue were mechanically disrupted by sterile scissors and homogenized using QIAshredder (Qiagen, Hamburg, Germany) according to manufacturer's instructions. RNA was extracted using RNeasy mini kit (Qiagen, Hamburg, Germany) and eluted in a final volume of $50 \mu \mathrm{l}$. Samples purity was assessed by NanoDrop ND-2000 spectrophotometer (Thermo Fisher Scientific, Wilmington, DE, USA). Reverse transcription was performed on $200 \mathrm{ng}$ of extracted RNA in a $20 \mu$ total 
reaction volume using QuantiTect reverse transcription kit (Qiagen, Hamburg, Germany) as follows: samples were incubated for $2 \mathrm{~min}$ at $42{ }^{\circ} \mathrm{C}$ with gDNA Wipeout buffer to eliminate possible genomic DNA contamination, and then quickly put in ice, adding the reverse transcription mix containing also RNAse inhibitors. Optimized blend of oligo-dT and random primers were used as primers. Reaction conditions were as follows: at $45^{\circ} \mathrm{C}$ for $15 \mathrm{~min}$, at $95{ }^{\circ} \mathrm{C}$ for $3 \mathrm{~min}$ and at $4{ }^{\circ} \mathrm{C}$ for $5 \mathrm{~min}$. Obtained cDNA was quickly stored at $-20^{\circ} \mathrm{C}$, and relative gene expression analysis was performed on RotorGene 6000 (Corbett Research, Mortlake, Australia) by two-step quantitative PCR (qPCR) assay using SYBR green detection (Qiagen, Hamburg, Germany). Amplification was done in a $25 \mu \mathrm{l}$ final volume including $1 \mu \mathrm{l}$ of cDNA as template. The PCR master mix was prepared according to Qiagen protocol, and amplification conditions were as follows: $15 \mathrm{~min}$ at $95^{\circ} \mathrm{C}$ followed by 45 cycles $\left(94{ }^{\circ} \mathrm{C}\right.$ for $15 \mathrm{~s}, 55^{\circ} \mathrm{C}$ for $30 \mathrm{~s}$ and $72{ }^{\circ} \mathrm{C}$ for $30 \mathrm{~s}$ ). Melt curves were obtained at $95{ }^{\circ} \mathrm{C}$ for $15 \mathrm{~s}$. Amplicon length was assessed using $2 \%$ agarose gel electrophoresis using SYBR safe DNA gel stain (Invitrogen, Paisley, UK). The primer pairs used were from Qiagen (Hamburg, Germany). $\beta$-Actin primer was a custom primer: forward GGGAAATCGTGCGTGACATT (20 bp) and reverse GCGGCAGTGGCCATCTC (17 bp). Amplicon length was 76 bp on the recognized sequence NM_031144. Glyceraldehyde-3-phosphate-dehydrogenase (Gapdh) and $\beta$-actin were chosen as reference genes given that it is reported that fish oil supplementation has no effect on GAPDH expression (Xu et al. 2002); moreover, $\beta$-actin was previously used in gene expression study involving PUFA supplementation (Caplan et al. 2001; Vara Prasad et al. 2010). Primer specificity was evaluated using a melt curve that showed unique specific peak in all cases. qPCR validation was carried out by standard curve. Reaction efficiency and $R$ value were in the range of $80-100 \%$ and 0.99 , respectively, for all examined genes. Three expression technical replicates were performed on reverse transcription duplicates. Seven biological replicates for each experimental group were used. Relative quantification of the mRNA levels of all examined genes was determined using the RotorGene 6000 software 1.7 comparative quantification analysis, in which reaction efficiency is calculated on each reaction tube. All samples used had $>85 \%$ efficiency.

\section{Protein extraction and western blotting (WB)}

Total proteins were extracted from $200 \mathrm{mg}$ liver using T-PER tissue protein extraction reagent in presence of $1 \%$ halt protease inhibitor cocktail according to the manufacturer (Thermo Fisher Scientific, Pittsburgh, PA, USA). The amount and purity of proteins were assessed using a
NanoDrop ND-2000 spectrophotometer (Thermo Fisher Scientific, Wilmington, DE, USA).

Fifty micrograms of proteins from each sample was fractionated by $8 \%$ SDS-PAGE gel $(90 \mathrm{mV}$ for $20 \mathrm{~min}$ and then $120 \mathrm{mV}$ for $80 \mathrm{~min})$, and transferred $(100 \mathrm{mV}$, $120 \mathrm{~min}$ ) onto a nitrocellulose membrane (GE Healthcare, Buckinghamshire, UK). The membrane was blocked with Tris-buffered saline tween-20 (TBST) containing $5 \%$ fatfree milk for $1 \mathrm{~h}$ at room temperature, and incubated overnight at $4{ }^{\circ} \mathrm{C}$ with primary antibodies directed against SREBP-1 (1:500), SREBP-2 (1:250), LDLR (1:500), HMGCR $(1: 1,000)$ and ACAT-2 $(1: 2,000)$, respectively. After washing 3 times with TBST, the membrane was incubated with horseradish-peroxidase conjugated secondary anti-mouse (Sigma Chemical Co., Milan, Italy) or antirabbit (AbCam, Cambridge, UK) antibodies at room temperature for $1 \mathrm{~h}$. Immunoreactive bands were visualized with an enhanced chemiluminescence kit (GE Healthcare, Buckinghamshire, UK) on ChemiDoc MP System and quantified by Image Lab software version 4.0 (Bio-Rad Laboratories, Hercules, CA, USA). The intensities of bands were expressed relative to the actin intensities (antibody incubation overnight $4{ }^{\circ} \mathrm{C}$ at the concentration of $1: 1,000$ ) from the same membrane restored using restore plus western blot stripping buffer (Thermo Fisher Scientific, Pittsburgh, PA, USA) for 15 min in soft shaking.

\section{Statistical analysis}

Statistical analysis for body weight, lipid profile, FA composition and protein expression data was performed by the one-way ANOVA with Tukey's as post-test. Statistical analysis of gene expression data was performed by REST 2009 software in RotorGene (RG) mode that uses Taylor's series to find statistical differences, as shown by Pfaffl et al. (2002). Gene expression was normalized on the reference genes Gapdh and $\beta$-actin, and all sample groups were referred to WK-St rats (calibrator group). This normalization underlines fold-changes between sample and the calibrator group (WK-St) that becomes the baseline.

\section{Results}

Although in the beginning of the trial $\mathrm{SH}$ rats appeared smaller in size than WK counterparts, and their increase in body weight along the dietary intervention was lower, within each strain no differences ascribable to the n-3 LCPUFA supplementation in body weight gain and food consumption were detected (data not shown).

The FA composition of plasma total lipid (Fig. 1a) showed in SH-St rats a higher content of arachidonic acid (20:4 n-6, AA), and a lower content of linoleic (18:2 n-6, 
LA) and $\alpha$-linolenic acid (C 18:3 n-3, ALA) than in WKSt. EPA and DHA plasma concentration increased in both PUFA-fed groups, confirming the absorption of the supplemented FA. In WK rats this increase was through a decrease in LA and ALA content, while in SH ones through a decrease in AA content.

No differences in liver FA composition were detected between standard diets fed animals (Fig. 1b); in both groups, dietary EPA and DHA were incorporated also in the hepatic tissue, mainly at the expense of AA.

When fed the standard diet, SH rats evidenced lower TOT-C, HDL-C, and triglyceride (TG) plasma levels, a higher LDL-C plasma concentration and an almost doubled AI compared to WK animals (Table 1). The PUFA diet decreased TOT-C and TG concentration in both groups; in $\mathrm{SH}$ rats, a decrease in LDL-C and an increase in HDL-C were also observed. Consequently, the AI, extremely higher in SH-St rats than in the WK counterparts, was significantly reduced by the PUFA diet.
Srebf-1 gene expression (Fig. 2a) was similar in WK and $\mathrm{SH}$ rats fed the standard diet, and it was down-regulated in SH-PUFA animals compared to both standard fed groups and WK-PUFA. In standard condition, the expression of the uncleaved form of SREBP-1 was significantly lower in the SH strain (Fig. 2b), while the level of the cleaved protein was similar (Fig. 2c); for both the inactive and active form, no modification ascribable to the PUFA diet were detected.

No differences ascribable to the strain or the diet were detected in Srebf-2 gene expression (Fig. 3a). In the two strains of standard diet-fed animals, the expression of both uncleaved and cleaved SREBP-2 protein was similar, and appeared decreased by the PUFA diet in the WK one only (Fig. 3b, c).

Although in standard diet-fed animals no difference was observed in Hmgcr gene expression between the WK and SH strains (Fig. 4a), HMGCR protein level was significantly lower in the latter than in the former (Fig. 4b). The
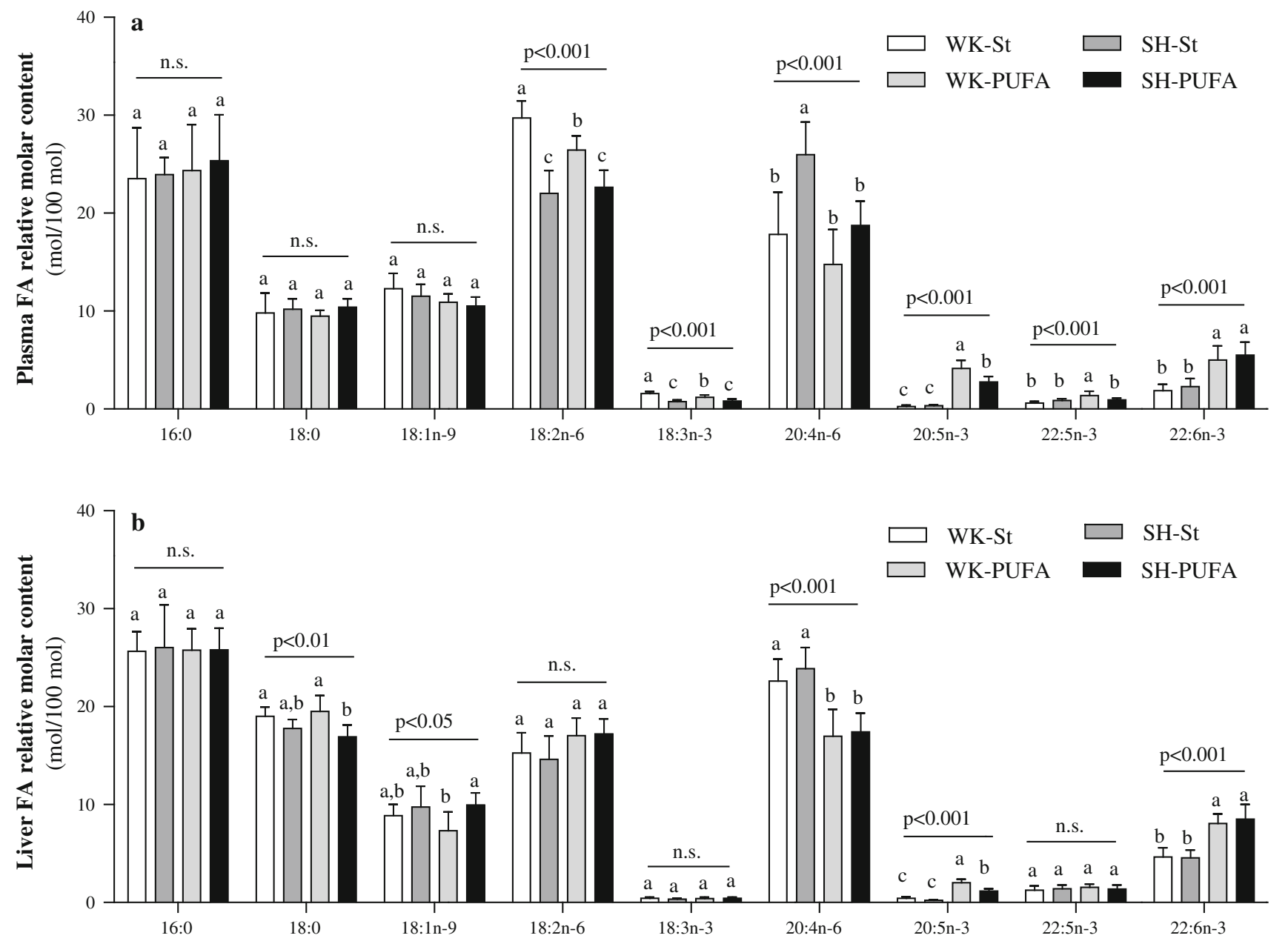

Fig. 1 Plasma (a) and liver (b) total lipid fatty acid composition in WK and SH rats fed the different diets. Data are mean \pm SD of seven animals per group. Statistical analysis was performed by the one-way
ANOVA using Tukey's as post-test. For each fatty acid, bars with different superscript letters are significantly different (at least $p<0.05)$ 
Table 1 Plasma lipid profile in WK and SH rats after the dietary treatment

\begin{tabular}{lcccc}
\hline & WK-St & SH-St & WK-PUFA & SH-PUFA \\
\hline TOT-C (mg/dl) & $107.60 \pm 2.70^{\mathrm{a}}$ & $91.60 \pm 4.83^{\mathrm{b}}$ & $88.40 \pm 2.30^{\mathrm{b}}$ & $73.40 \pm 3.65^{\mathrm{c}}$ \\
HDL-C (mg/dl) & $41.80 \pm 2.49^{\mathrm{a}}$ & $26.00 \pm 3.74^{\mathrm{c}}$ & $37.20 \pm 2.28^{\mathrm{a}, \mathrm{b}}$ & $31.20 \pm 5.85^{\mathrm{b}}$ \\
LDL-C (mg/dl) & $26.24 \pm 6.19^{\mathrm{b}}$ & $41.48 \pm 9.57^{\mathrm{a}}$ & $25.48 \pm 3.04^{\mathrm{b}}$ & $23.88 \pm 6.14^{\mathrm{b}}$ \\
TG (mg/dl) & $197.80 \pm 14.20^{\mathrm{a}}$ & $120.60 \pm 12.50^{\mathrm{b}}$ & $128.60 \pm 12.44^{\mathrm{b}}$ & $91.60 \pm 11.28^{\mathrm{c}}$ \\
AI & $1.44 \pm 0.29^{\mathrm{b}}$ & $2.59 \pm 0.60^{\mathrm{a}}$ & $1.38 \pm 0.14^{\mathrm{b}}$ & $1.41 \pm 0.41^{\mathrm{b}}$ \\
\hline
\end{tabular}

Data are mean \pm SD of seven animals per group. Statistical analysis was performed by the one-way ANOVA $(p<0.001$ for all tested parameters) using Tukey's as post-test, which allowed a multiple comparison among the four groups. In each row, values with different superscript letters are significantly different (at least $p<0.05$ )

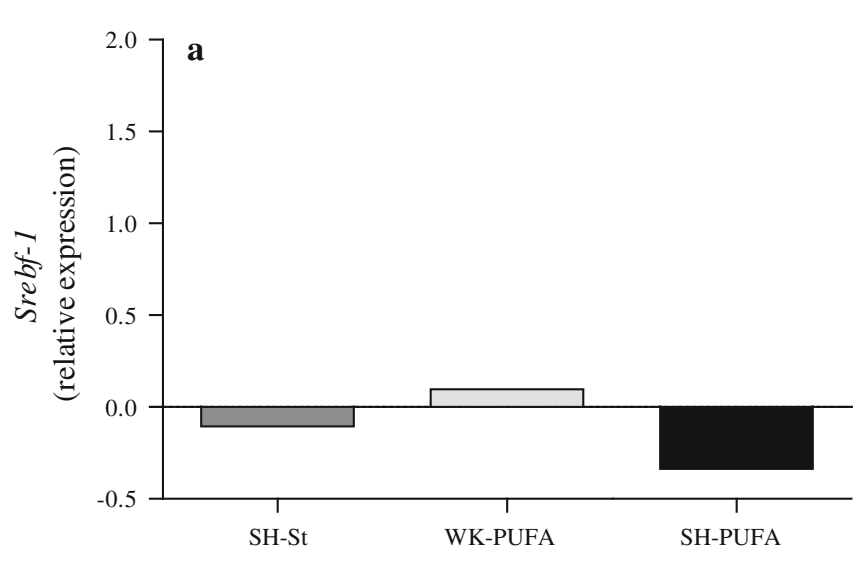

\begin{tabular}{|c|c|c|c|}
\hline & median expression & range (min - max) & $95 \%$ C.I. \\
\hline WK-St & 1 & - & - \\
\hline $\mathrm{SH}-\mathrm{St}$ & 0.894 & $0.654-1.321$ & $0.563-2.051$ \\
\hline WK-PUFA & 1.097 & $0.671-1.506$ & $0.559-2.920$ \\
\hline SH-PUFA & 0.663 & $0.471-0.988$ & $0.421-1.522$ \\
\hline \multicolumn{2}{|c|}{ statistic pairs } & p-value & result \\
\hline WK-St & SH-St & 0.440 & not changed \\
\hline WK-St & WK-PUFA & 0.602 & not changed \\
\hline WK-St & SH-PUFA & 0.023 & DOWN \\
\hline $\mathrm{SH}-\mathrm{St}$ & SH-PUFA & 0.021 & DOWN \\
\hline WK-PUFA & SH-PUFA & 0.008 & DOWN \\
\hline $\mathrm{SH}-\mathrm{St}$ & WK-PUFA & 0.158 & not changed \\
\hline
\end{tabular}
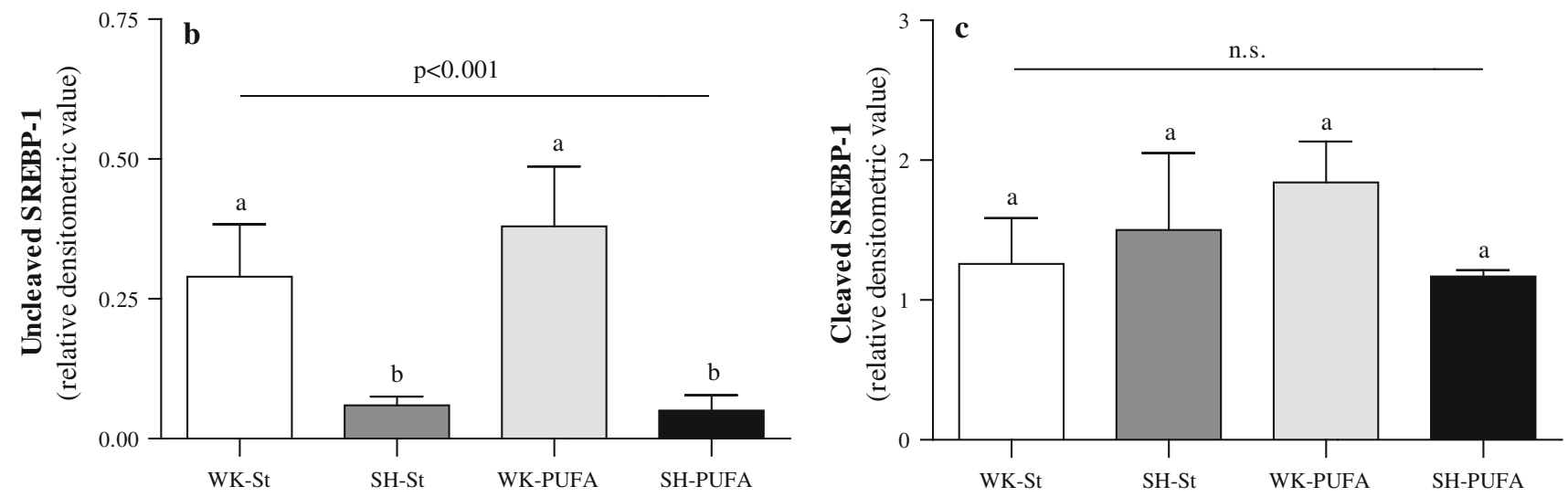

Fig. 2 SREBP-1 gene (a) and protein (b, c) expression in the liver of WK and SH rats fed the different diets. Srebpf-1 expression (a). Data in the graph are represented as [(sample ratio) - (unitary calibrator group ratio)]; significant differences were evaluated with Taylor's series statistical analysis. Gene expression in each group $(n=7)$ is reported as median, range (min-max), and $95 \% \mathrm{CI}$ in the corresponding table, where statistic pairs, $p$ value and resulting

n-3 LC-PUFA supplementation decreased Hmgcr transcription and the level of the encoded protein in both WK and $\mathrm{SH}$ animals compared to their standard diet-fed counterparts; Hmgcr transcription was similar in WKPUFA and SH-PUFA rats, while HMGCR protein level was significantly higher in the former than in the latter group. differences are also indicated. Uncleaved (b) and cleaved (c) SREBP1 protein expression. Data in the graphs are mean \pm SD of four animals per group and are represented as densitometric value normalized on actin. Statistical analysis was performed by the oneway ANOVA using Tukey's as post-test; different superscript letters indicate statistical significance (at least $p<0.05$ )

In standard diet-fed animals, Ldlr gene (Fig. 5a) and LDLR protein (Fig. 5b) expression were higher in the $\mathrm{SH}$ than in the WK strain. In the latter, they were not modified by the PUFA diet, while they were down-regulated in the former.

Finally, Acat-2 gene expression was higher in the $\mathrm{SH}-\mathrm{St}$ than in the WK-St rats, and it was further up-regulated in 


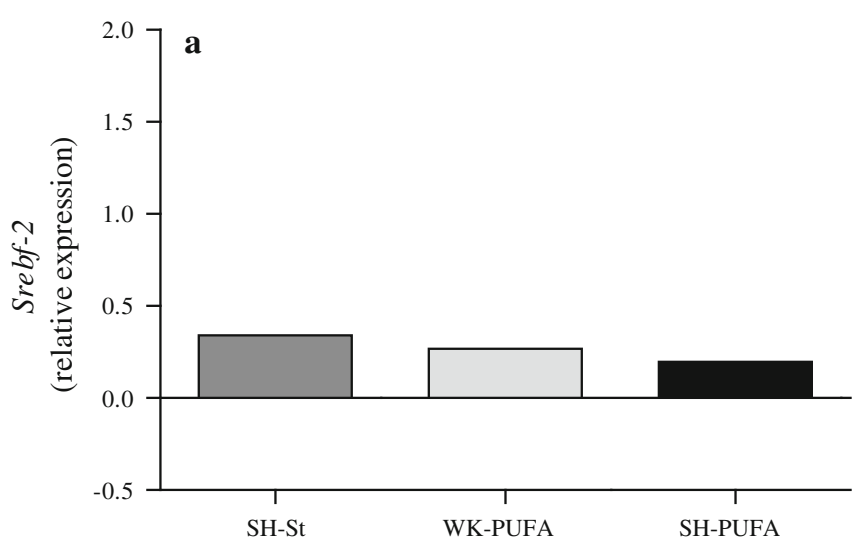

\begin{tabular}{|c|c|c|c|}
\hline & median expression & range (min - max) & $\mathbf{9 5 \%}$ C.I. \\
\hline WK-St & 1 & - & - \\
SH-St & 1.340 & $0.916-1.965$ & $0.694-2.758$ \\
\hline WK-PUFA & 1.268 & $0.827-1.806$ & $0.619-2.898$ \\
\hline SH-PUFA & 1.197 & $0.814-1.543$ & $0.719-2.066$ \\
\hline \multicolumn{2}{|c|}{ statistic pairs } & p-value & result \\
\hline WK-St & SH-St & 0.074 & not changed \\
WK-St & WK-PUFA & 0.218 & not changed \\
WK-St & SH-PUFA & 0.184 & not changed \\
SH-St & SH-PUFA & 0.180 & not changed \\
\hline WK-PUFA & SH-PUFA & 0.729 & not changed \\
SH-St & WK-PUFA & 0.750 & not changed \\
\hline
\end{tabular}
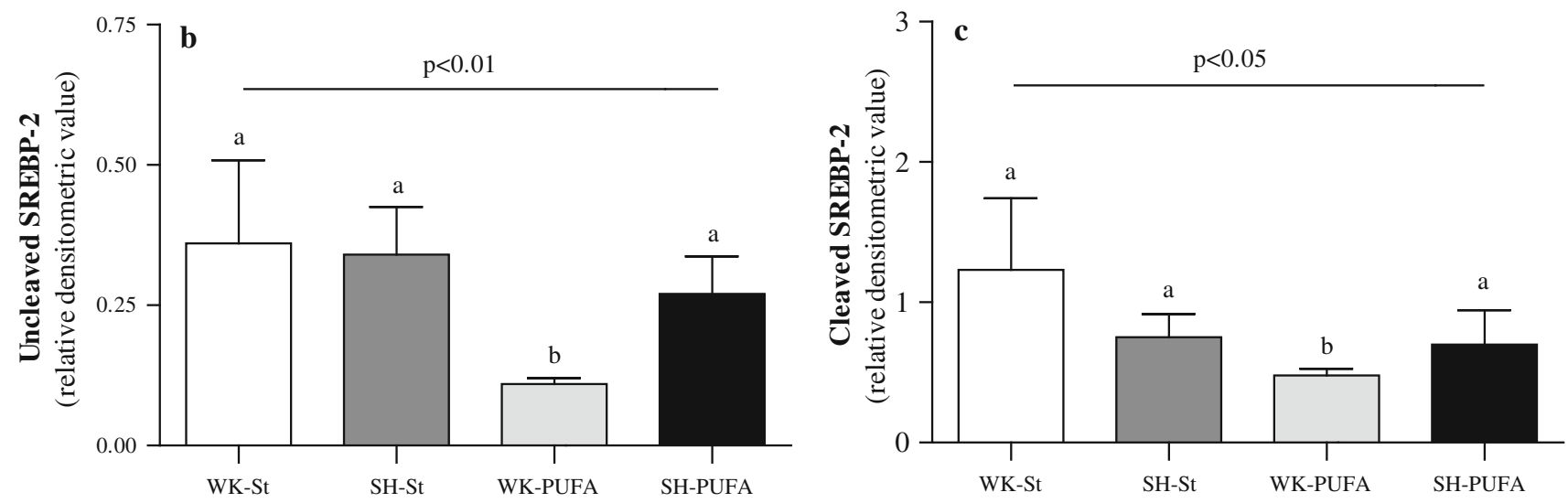

Fig. 3 SREBP-2 gene (a) and protein (b, c) expression in the liver of WK and SH rats fed the different diets. Srebpf-2 expression (a). Data in the graph are represented as [(sample ratio) - (unitary calibrator group ratio)]; significant differences were evaluated with Taylor's series statistical analysis. Gene expression in each group $(n=7)$ is reported as median, range (min-max), and $95 \% \mathrm{CI}$ in the corresponding table, where statistic pairs, $p$ value and resulting

the SH-PUFA compared to both standard fed groups and WK-PUFA; notwithstanding no significant differences related to strain or diet were detected in the encoded protein level (Fig. 6a, b, respectively).

\section{Discussion}

It is becoming increasingly apparent that responsiveness to dietary fat composition is highly heterogeneous and dependent on the genetic make-up of the individual. The aim of this study was to verify the influence of different genotypes on the modulation of the expression of selected genes in response to EPA and DHA dietary supplementation, using WK and $\mathrm{SH}$ rats as a model.

As indicated by the plasma and liver FA composition, in both strains the supplemented FA were absorbed, and incorporated in liver mainly at the expense of AA, reflecting the previously reported metabolic competition differences are also indicated. Uncleaved (b) and cleaved (c) SREBP2 protein expression. Data in the graphs are mean \pm SD of four animals per group and are represented as densitometric value normalized on actin. Statistical analysis was performed by the oneway ANOVA using Tukey's as post-test; different superscript letters indicate statistical significance (at least $p<0.05$ )

between the two PUFA families (Mu et al. 2006; Simopoulos 2008).

The PUFA diet significantly and positively modified lipemic values in both strains, decreasing TOT-C and TG level. These modifications, as well as the decrease in LDL$\mathrm{C}$ and the increase in HDL-C, significantly reduced the AI in $\mathrm{SH}$ rats. Dyslipidaemia is one of the principal causative factor contributing to the atherogenic processes (Steinberg 2004), and the AI is commonly used as the finest lipid parameter to predict human CVD risk (Vinson et al. 2001). The AI lowering effect of n-3 LC-PUFA has been previously reported by Deutch et al. (2000) and Kabir et al. (2007) in women, and our data confirm the importance of EPA and DHA in the prevention of dyslipidaemia and related diseases, emphasizing the need of a better understanding of the molecular process involved.

The transcriptional response to dietary PUFA appeared greatly affected by genotype; in fact, the expression of 4 out of 5 genes (Srebpf-1, Hmgcr, Ldlr, and Acat-2) 

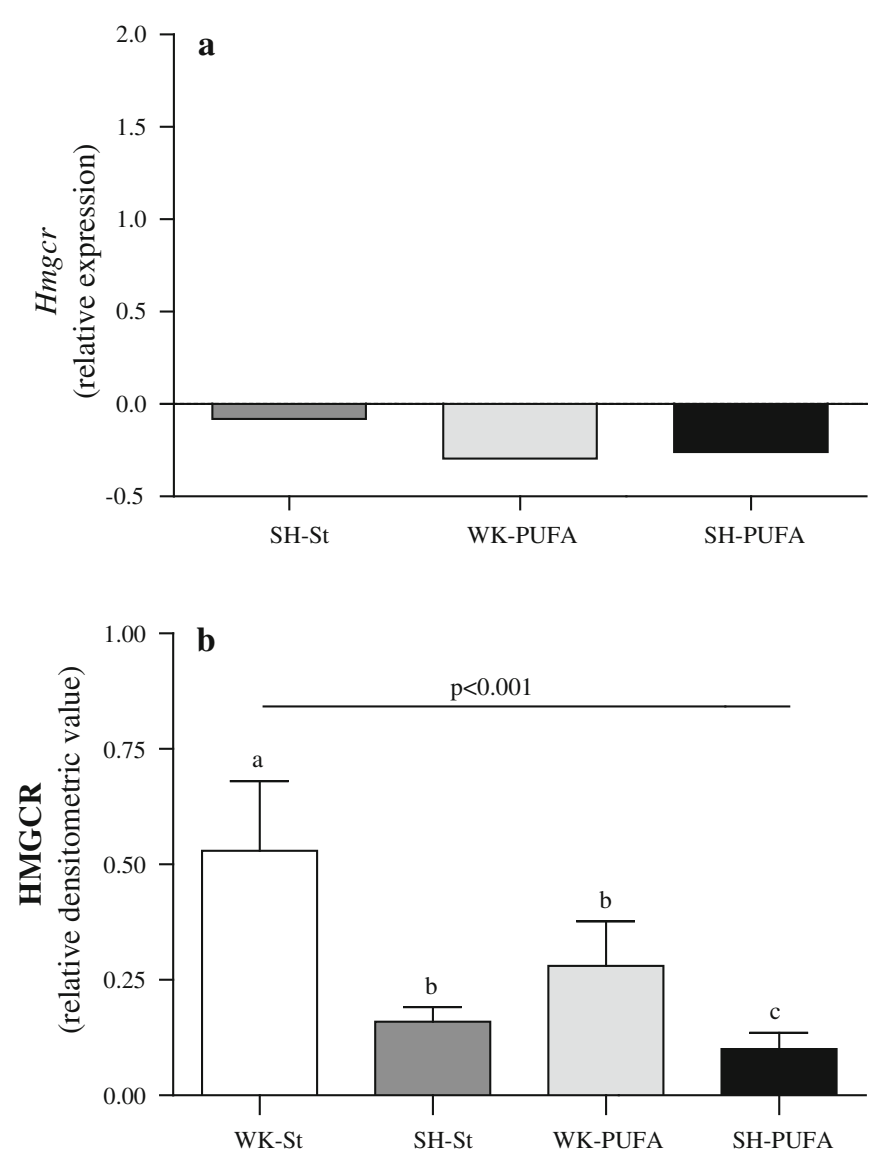

Fig. 4 HMGCR gene (a) and protein (b) expression in the liver of WK and SH rats fed the different diets. Hmgcr gene expression (a). Data in the graph are represented as [(sample ratio) - (unitary calibrator group ratio)]; significant differences were evaluated with Taylor's series statistical analysis. Gene expression in each group $(n=7)$ is reported as median, range (min-max), and $95 \% \mathrm{CI}$ in the corresponding table, where statistic pairs, $p$ value and resulting

appeared modulated in SH animals, while only Hmgcr was down-regulated in WK ones. The impact of the genetic variation was less evident considering the level of the corresponding proteins, confirming that gene expression at the mRNA level is generally informative but not predictive for that at the protein level.

Although EPA and DHA effect on Srebf-1 expression was influenced by the genetic variation, no significant modifications in the level of both uncleaved and cleaved SREBP-1 were detected upon PUFA supplementation in either WK or SH rats. This discrepancy from previous studies could be dependent on the different experimental model, that is in vivo study versus cultured liver cells (Kohan et al. 2011), to the different FA concentration in the diet and to the different length of the dietary treatment $(\mathrm{Lu}$ et al. 2011), or to the use of purified EPA and DHA in spite of oils for dietary supplementation (Yang et al. 2011). Although the inability of PUFA in modifying active

\begin{tabular}{|c|c|c|c|}
\hline & median expression & range (min - max) & 95\% C.I. \\
\hline WK-St & 1 & - & - \\
SH-St & 0.921 & $0.622-1.333$ & $0.486-1.698$ \\
WK-PUFA & 0.706 & $0.475-1.053$ & $0.372-1.389$ \\
SH-PUFA & 0.741 & $0.539-1.041$ & $0.385-1.321$ \\
\multicolumn{2}{|c|}{ statistic pairs } & p-value & result \\
\hline WK-St & SH-St & 0.566 & not changed \\
WK-St & WK-PUFA & 0.047 & DOWN \\
WK-St & SH-PUFA & 0.060 & not changed \\
SH-St & SH-PUFA & 0.040 & DOWN \\
WK-PUFA & SH-PUFA & 0.743 & not changed \\
SH-St & WK-PUFA & 0.034 & DOWN \\
\hline
\end{tabular}

differences are also indicated. HMGCR protein expression (b). Data in the graph are mean $\pm \mathrm{SD}$ of four animals per group and are represented as densitometric value normalized on actin. Statistical analysis was performed by the one-way ANOVA using Tukey's as post-test; different superscript letters indicate statistical significance (at least $p<0.05$ )

SREBP-1 level in our experimental condition, as well as the low level of uncleaved SREBP-1 observed in SH rats, deserves further attention to our aim, the most relevant data were the evidence of a different modulation of Srebpf-1 expression by PUFA in the two strains.

It is well documented that n-3 LC-PUFA do not interfere with Srebpf-2 transcription, and they inhibit the activating cleavage of SREBP-2 via indirect mechanisms involving increased flow of free cholesterol between the plasma membrane and intracellular membranes (Di Nunzio et al. 2010; Ma et al. 2004). Accordingly, Srebpf-2 gene expression was not modified by PUFA in both strains; notably the modulation of SREBP-2 cleavage by EPA and DHA was detected in WK rats only.

According to Notarnicola et al. (2010) in both WK and SH strain, the PUFA diet caused a down-regulation of Hmgcr transcription and translation, which was consistent with the observed decrease in plasma TOT-C after the 

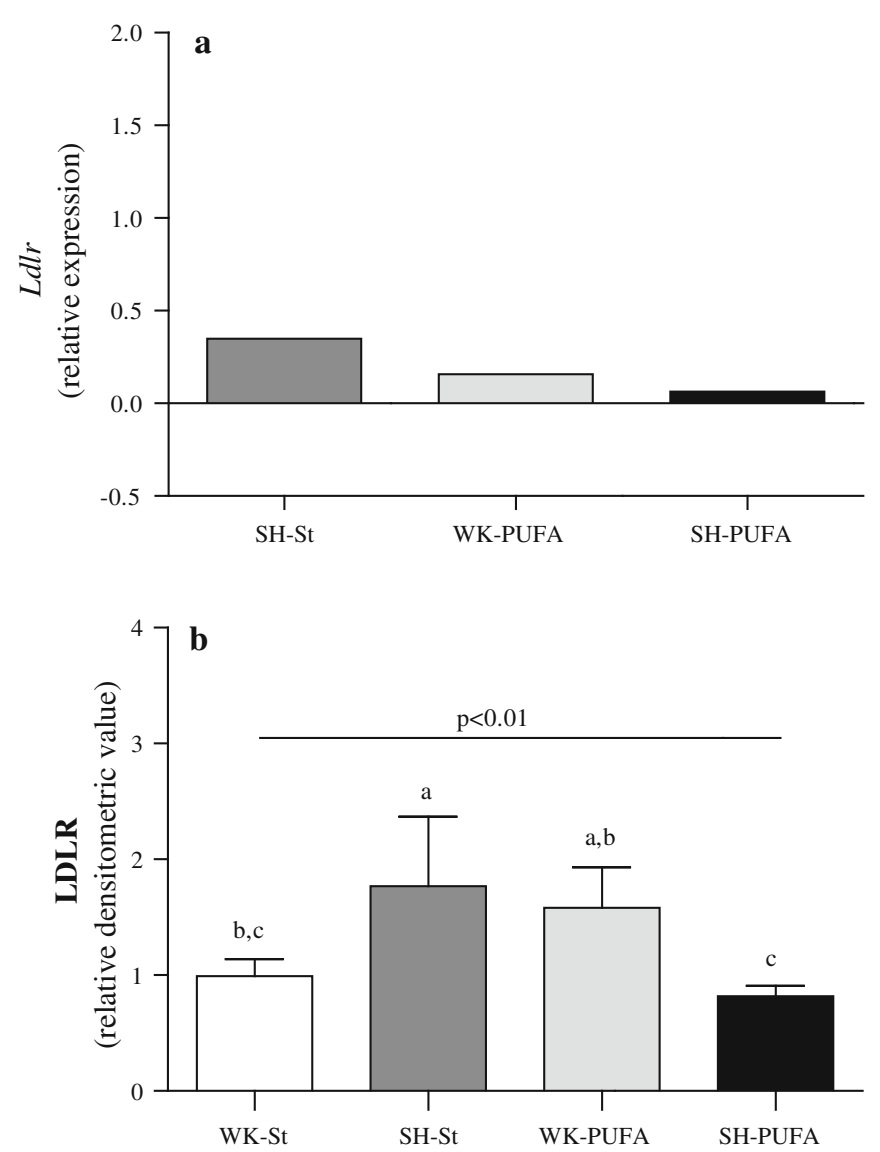

Fig. 5 LDLR gene (a) and protein (b) expression in the liver of WK and $\mathrm{SH}$ rats fed the different diets. $L d l r$ gene expression (a). Data in the graph are represented as [(sample ratio) - (unitary calibrator group ratio)]; significant differences were evaluated with Taylor's series statistical analysis. Gene expression in each group $(n=7)$ is reported as median, range (min-max), and $95 \%$ CI in the corresponding table, where statistic pairs, $p$ value and resulting

dietary intervention. Although Hmgcr expression is considered to be controlled by SREBPs (Fuhrman et al. 2007), the different SREBP-2 level after the dietary treatment let us hypothesize different mechanisms and transcription factors for the PUFA-induced reduction in Hmgcr expression in the two strains. As a possibility, unsaturated FA have been recognized as ligands for the orphan nuclear receptor Nur77 (Vinayavekhin and Saghatelian 2011) that has been recently shown to regulate HMGCR expression in cultured liver cells (Zhang et al. 2012).

The differential effect of PUFA in the two genotypes was particularly evident for LDLR. In WK rats, the treatment caused an increase in LDLR protein expression, as already reported in HepG2 cells (Yu-Poth et al. 2005), without any modification in gene expression, while in the SH strain, EPA + DHA supplementation reduced both gene and protein expression. The decreased LDLR level in SH-PUFA rats could appear in contrast to the observed

\begin{tabular}{|c|c|c|c|}
\hline & median expression & range (min - max) & $\mathbf{9 5 \% ~ C . I . ~}$ \\
\hline WK-St & 1 & - & - \\
SH-St & 1.349 & $1.157-1.603$ & $0.895-1.828$ \\
WK-PUFA & 1.157 & $0.927-1.438$ & $0.706-2.031$ \\
\hline SH-PUFA & 1.063 & $0.852-1.306$ & $0.694-1.487$ \\
\hline \multicolumn{2}{|c|}{ statistic pairs } & p-value & result \\
\hline WK-St & SH-St & 0.002 & UP \\
WK-St & WK-PUFA & 0.216 & not changed \\
WK-St & SH-PUFA & 0.511 & not changed \\
SH-St & SH-PUFA & 0.001 & DOWN \\
WK-PUFA & SH-PUFA & 0.393 & not changed \\
SH-St & WK-PUFA & 0.099 & not changed \\
\hline
\end{tabular}

differences are also indicated. LDLR protein expression (b). Data in the graph are mean \pm SD of four animals per group and are represented as densitometric value normalized on actin. Statistical analysis was performed by the one-way ANOVA using Tukey's as post-test; different superscript letters indicate statistical significance (at least $p<0.05$ )

decrease in plasma LDL-C, but it is worth noting that in rats, most of the cholesterol taken up into the liver from serum is HDL-C rather than LDL-C, serum LDL-C being regulated more by cholesterol and LDL biosynthesis than by liver LDL uptake (Tsutsumi et al. 2001). The effect of PUFA on Ldlr transcription is controversial, and both down- and up-regulations have been observed (Lindsey et al. 1992; Zheng et al. 2002). Our data suggest that the modulation of LDLR gene and protein expression by PUFA is also related to genotypes, and involves mechanisms and transcription factors other than SREBP-1 and -2. A dual control system (on the synthesis and on the degradation end) of hepatic LDLR expression is currently recognized (Attie and Seidah 2005), and different observations support a SREBP-independent PUFA effect on the regulation of LDLR level (Bjermo et al. 2012; Kuang et al. 2012). Furthermore, Yu-Poth et al. (2005) suggested that PUFA may regulate LDLR expression via a pathway that is 

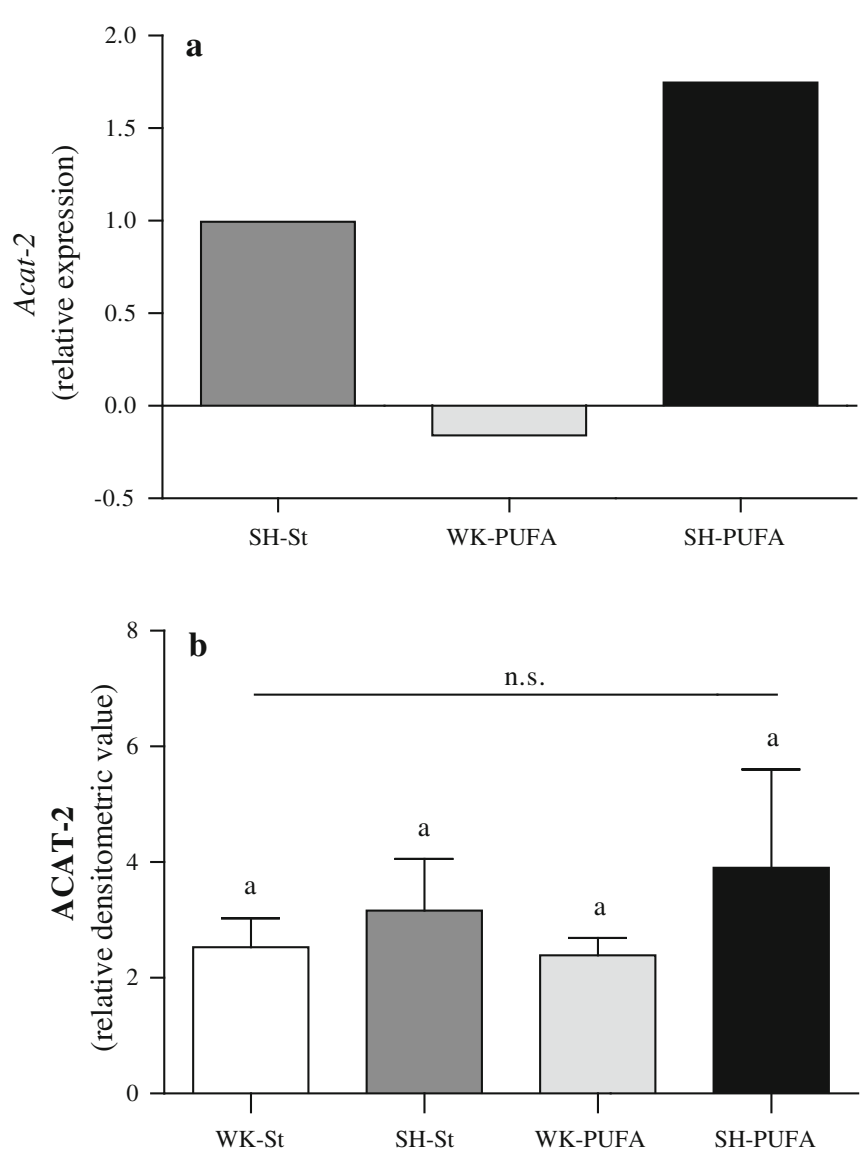

Fig. 6 ACAT-2 gene (a) and protein (b) expression in the liver of WK and SH rats fed the different diets. Acat-2 gene expression (a). Data in the graph are represented as [(sample ratio) - (unitary calibrator group ratio)]; significant differences were evaluated with Taylor's series statistical analysis. Gene expression in each group $(n=7)$ is reported as median, range (min-max), and $95 \% \mathrm{CI}$ in the corresponding table, where statistic pairs, $p$ value and resulting

independent of SREBP and involves ACAT activity. In this study, Acat gene expression was up-regulated by PUFA in SH animals, and the level of the encoded protein increased although not reaching significant value. Lin et al. (2004) evidenced in hamsters that the amount of dietary cholesterol is an important factor in determining the mode and extent of effects of dietary n-3 LC-PUFA on ACAT; our data indicate that also genotype has a role in the final response.

In conclusion, our data confirm the positive effect of EPA and DHA on the serum lipid profile in both WK and SH rats, but despite the similar final outcomes gene and protein expression analyses showed differential, genotyperelated effect of n-3 LC-PUFA. In recent years, a more comprehensive understanding of the impact of PUFA intake on the regulation of genes involved in lipogenesis

\begin{tabular}{|c|c|c|c|}
\hline & median expression & range (min - max & 95\% C.I. \\
\hline WK-St & 1 & - & - \\
SH-St & 1.994 & $1.443-2.762$ & $1.084-3.486$ \\
WK-PUFA & 0.841 & $0.613-1.176$ & $0.441-1.468$ \\
\hline SH-PUFA & 2.747 & $2.010-3.831$ & $1.374-4.804$ \\
\multicolumn{2}{|r|}{ statistic pairs } & p-value & result \\
\hline WK-St & SH-St & 0.002 & UP \\
\hline WK-St & WK-PUFA & 0.212 & not changed \\
\hline WK-St & SH-PUFA & $<0.001$ & UP \\
\hline SH-St & SH-PUFA & 0.021 & UP \\
\hline WK-PUFA & SH-PUFA & $<0.001$ & UP \\
\hline SH-St & WK-PUFA & $<0.001$ & DOWN \\
\hline
\end{tabular}

differences are also indicated. ACAT-2 protein expression (b). Data in the graph are mean \pm SD of 4 animals per group and are represented as densitometric value normalized on actin. Statistical analysis was performed by the one-way ANOVA using Tukey's as post-test; different superscript letters indicate statistical significance (at least $p<0.05$ )

has emerged, and a number of common gene variants have been identified which may be important determinants of the blood lipid response to altered dietary fat composition. The authors are aware that the use of animals represents a limitation of the present study, but it allowed to strictly regulate the diet and to investigate defined genetic models in order to check diet-gene interaction evaluating the modulation of the effect of specific nutrients due to genetic variants.

The reported different influence of n-3 LC-PUFA on the expression of specific gene and protein cannot attributed to single gene variations but rather to the whole genotype, and improve our scientific awareness of genotype influence on the effects of bioactive molecules. Although further studies are needed, the reported observations could contribute to ongoing nutrigenetics and nutrigenomics research aimed at 
the development of personalized dietary advice, optimized to suit the individual, that may also improve end-user motivation for dietary changes.

Acknowledgments This work was supported by a grant of SPA Antibiotics SpA (Milano, Italy) and by the Italian Ministry of the Economic Development (MIAOVER50 project).

\section{References}

Attie AD, Seidah NG (2005) Dual regulation of the LDL receptorsome clarity and new questions. Cell Metab 1:290-292. doi: 10.1016/j.cmet.2005.04.006

Bordoni A, Astolfi A, Morandi L, Pession A, Danesi F, Di Nunzio M, Franzoni M, Biagi P, Pession A (2007) n-3 PUFA modulate global gene expression profile in cultured rat cardiomyocytes. Implications in cardiac hypertrophy and heart failure. FEBS Lett 581:923-929. doi:10.1016/j.febslet.2007.01.070

Bjermo H, Iggman D, Kullberg J, Dahlman I, Johansson L, Persson L, Berglund J, Pulkki K, Basu S, Uusitupa M, Rudling M, Arner P, Cederholm T, Ahlstrom H, Riserus U (2012) Effects of n-6 PUFAs compared with SFAs on liver fat, lipoproteins, and inflammation in abdominal obesity: a randomized controlled trial. Am J Clin Nutr 95:1003-1012. doi:10.3945/ajcn.111. 030114

Caplan MS, Russell T, Xiao Y, Amer M, Kaup S, Jilling T (2001) Effect of polyunsaturated fatty acid (PUFA) supplementation on intestinal inflammation and necrotizing enterocolitis (NEC) in a neonatal rat model. Pediatr Res 49:647-652. doi:10.1203/0000 6450-200105000-00007

Choi JS, Yokozawa T, Oura H (1991) Antihyperlipidemic effect of flavonoids from Prunus davidiana. J Nat Prod 54:218-224. doi: $10.1021 / \mathrm{np} 50073 \mathrm{a} 022$

Corella D, Ordovás JM (2012) Interactions between dietary n-3 fatty acids and genetic variants and risk of disease. $\mathrm{Br} \mathrm{J}$ Nutr 107:S271-S283. doi:10.1017/S0007114512001651

Deutch B, Jorgensen EB, Hansen JC (2000) n-3 PUFA from fish- or seal oil reduce atherogenic risk indicators in Danish women. Nutr Res 20:1065-1077. doi:10.1016/S0271-5317(00)00205-0

Di Nunzio M, van Deursen D, Verhoeven AJ, Bordoni A (2010) n-3 and $n-6$ polyunsaturated fatty acids suppress sterol regulatory element binding protein activity and increase flow of nonesterified cholesterol in HepG2 cells. Br J Nutr 103:161-167. doi:10.1017/S000711450999167X

Folch J, Lees M, Sloane Stanley GH (1957) A simple method for the isolation and purification of total lipides from animal tissues. J Biol Chem 226:497-509

Friedewald WT, Levy RI, Fredrickson DS (1972) Estimation of the concentration of low-density lipoprotein cholesterol in plasma, without use of the preparative ultracentrifuge. Clin Chem 18:499-502

Fuhrman B, Nitzan O, Karry R, Volkova N, Dumler I, Aviram M (2007) Urokinase plasminogen activator (uPA) stimulates cholesterol biosynthesis in macrophages through activation of SREBP-1 in a PI3-kinase and MEK-dependent manner. Atherosclerosis 195:e108-e116. doi:10.1016/j.atherosclerosis.2007.06.025

Greenhouse DD, Festing MFW, Hasan S, Cohen AL (1990) Catalogue of inbred strains of rats. In: Hedrich HJ (ed) Genetic monitoring of inbred strains of rats. Gustav Fischer, Stuttgart, NY, pp 410-480

Horton JD, Goldstein JL, Brown MS (2002) SREBPs: activators of the complete program of cholesterol and fatty acid synthesis in the liver. J Clin Invest 109:1125-1131. doi:10.1172/JCI15593
Horton JD, Shah NA, Warrington JA, Anderson NN, Park SW, Brown MS, Goldstein JL (2003) Combined analysis of oligonucleotide microarray data from transgenic and knockout mice identifies direct SREBP target genes. Proc Natl Acad Sci USA 100:12027-12032. doi:10.1073/pnas. 1534923100

Johnson ML, Ely DL, Turner ME (1992) Genetic divergence between the Wistar-Kyoto rat and the spontaneously hypertensive rat. Hypertension 19:425-427. doi:10.1161/01.HYP.19.5.425

Kabir M, Skurnik G, Naour N, Pechtner V, Meugnier E, Rome S, Quignard-Boulange A, Vidal H, Slama G, Clement K, GuerreMillo M, Rizkalla SW (2007) Treatment for 2 mo with n 3 polyunsaturated fatty acids reduces adiposity and some atherogenic factors but does not improve insulin sensitivity in women with type 2 diabetes: a randomized controlled study. Am J Clin Nutr 86:1670-1679

Kohan AB, Qing Y, Cyphert HA, Tso P, Salati LM (2011) Chylomicron remnants and nonesterified fatty acids differ in their ability to inhibit genes involved in lipogenesis in rats. J Nutr 141:171-176. doi:10.3945/jn.110.129106

Kompauer I, Demmelmair H, Koletzko B, Bolte G, Linseisen J, Heinrich J (2005) Association of fatty acids in serum phospholipids with hay fever, specific and total immunoglobulin E. Br J Nutr 93:529-535. doi:10.1079/BJN20041387

Kuang YL, Eric Paulson K, Lichtenstein AH, Lamon-Fava S (2012) Regulation of the expression of key genes involved in HDL metabolism by unsaturated fatty acids. Br J Nutr 108:1351-1359. doi:10.1017/S0007114511006854

Laaksonen R, Thelen KM, Paiva H, Matinheikki J, Vesalainen R, Janatuinen T, Knuuti J, Rontu R, von Bergmann K, Lutjohann D, Lehtimaki T (2006) Genetic variant of the SREBF-1 gene is significantly related to cholesterol synthesis in man. Atherosclerosis 185:206-209. doi:10.1016/j.atherosclerosis.2005.06.007

Leaf A (2006) Prevention of sudden cardiac death by n-3 polyunsaturated fatty acids. Fundam Clin Pharmacol 20:525-538. doi: 10.1111/j.1472-8206.2006.00438.x

Lin MH, Lu SC, Huang PC, Liu YC, Liu SY (2004) The amount of dietary cholesterol changes the mode of effects of (n-3) polyunsaturated fatty acid on lipoprotein cholesterol in hamsters. Ann Nutr Metab 48:321-328. doi:10.1159/000081199

Lindsey S, Pronczuk A, Hayes KC (1992) Low density lipoprotein from humans supplemented with n-3 fatty acids depresses both LDL receptor activity and LDLr mRNA abundance in HepG2 cells. J Lipid Res 33:647-658

Lu J, Borthwick F, Hassanali Z, Wang Y, Mangat R, Ruth M, Shi D, Jaeschke A, Russell JC, Field CJ, Proctor SD, Vine DF (2011) Chronic dietary n-3 PUFA intervention improves dyslipidaemia and subsequent cardiovascular complications in the JCR:LA- cp rat model of the metabolic syndrome. Br J Nutr 105:1572-1582. doi:10.1017/S0007114510005453

Ma DW, Seo J, Switzer KC, Fan YY, McMurray DN, Lupton JR, Chapkin RS (2004) n-3 PUFA and membrane microdomains: a new frontier in bioactive lipid research. $J$ Nutr Biochem 15:700-706. doi:10.1016/j.jnutbio.2004.08.002

Madden J, Williams CM, Calder PC, Lietz G, Miles EA, Cordell H, Mathers JC, Minihane AM (2011) The impact of common gene variants on the response of biomarkers of cardiovascular disease (CVD) risk to increased fish oil fatty acids intakes. Annu Rev Nutr 31:203-234. doi:10.1146/annurev-nutr-010411-095239

Mu H, Thogersen RL, Maaetoft-Udsen K, Straarup EM, Frokiaer H (2006) Different kinetic in incorporation and depletion of n-3 fatty acids in erythrocytes and leukocytes of mice. Lipids 41:749-752. doi:10.1007/s11745-006-5026-5

Muskiet FA, Kemperman RF (2006) Folate and long-chain polyunsaturated fatty acids in psychiatric disease. J Nutr Biochem 17:717-727. doi:10.1016/j.jnutbio.2006.02.001 
Notarnicola M, Messa C, Refolo MG, Tutino V, Miccolis A, Caruso MG (2010) Synergic effect of eicosapentaenoic acid and lovastatin on gene expression of HMGCoA reductase and LDL receptor in cultured HepG2 cells. Lipids Health Dis 9:135. doi: 10.1186/1476-511X-9-135

Okamoto K, Aoki K (1963) Development of a strain of spontaneously hypertensive rats. Jpn Circ J 27:282-293

Pfaffl MW, Horgan GW, Dempfle L (2002) Relative expression software tool (REST) for group-wise comparison and statistical analysis of relative expression results in real-time PCR. Nucleic Acids Res 30:e36. doi:10.1093/nar/30.9.e36

Pravenec M, Jansa P, Kostka V, Zidek V, Kren V, Forejt J, Kurtz TW (2001) Identification of a mutation in ADD1/SREBP-1 in the spontaneously hypertensive rat. Mamm Genome 12:295-298. doi:10.1007/s003350010273

Pravenec M, Kazdova L, Landa V, Zidek V, Mlejnek P, Simakova M, Jansa P, Forejt J, Kren V, Krenova D, Qi N, Wang JM, Chan D, Aitman TJ, Kurtz TW (2008) Identification of mutated Srebf1 as a QTL influencing risk for hepatic steatosis in the spontaneously hypertensive rat. Hypertension 51:148-153. doi:10.1161/HYPE RTENSIONAHA.107.100743

Raghow R, Yellaturu C, Deng X, Park EA, Elam MB (2008) SREBPs: the crossroads of physiological and pathological lipid homeostasis. Trends Endocrinol Metab 19:65-73. doi:10.1016/ j.tem.2007.10.009

Righi V, Di Nunzio M, Danesi F, Schenetti L, Mucci A, Boschetti E, Biagi P, Bonora S, Tugnoli V, Bordoni A (2011) EPA or DHA supplementation increases triacylglycerol, but not phospholipid, levels in isolated rat cardiomyocytes. Lipids 46:627-636. doi: 10.1007/s11745-011-3562-0

Shimomura I, Shimano H, Horton JD, Goldstein JL, Brown MS (1997) Differential expression of exons 1a and 1c in mRNAs for sterol regulatory element binding protein- 1 in human and mouse organs and cultured cells. J Clin Invest 99:838-845. doi:10.1172/ JCI1 19247

Simopoulos AP (2008) The importance of the omega-6/omega-3 fatty acid ratio in cardiovascular disease and other chronic diseases. Exp Biol Med (Maywood) 233:674-688. doi:10.3181/0711MR-311

Steinberg D (2004) Thematic review series: the pathogenesis of atherosclerosis. An interpretive history of the cholesterol controversy: part I. J Lipid Res 45:1583-1593. doi:10.1194/jlr. R400003-JLR200

Stoffel W, Chu F, Ahrens EH (1959) Analysis of long-chain fatty acids by gas-liquid chromatography. Micromethod for preparation of methyl esters. Anal Chem 31:307-308. doi:10.1021/ ac60146a047

Trak-Fellermeier MA, Brasche S, Winkler G, Koletzko B, Heinrich J (2004) Food and fatty acid intake and atopic disease in adults. Eur Respir J 23:575-582. doi:10.1183/09031936.04.00074404
Tsutsumi K, Hagi A, Inoue Y (2001) The relationship between plasma high density lipoprotein cholesterol levels and cholesteryl ester transfer protein activity in six species of healthy experimental animals. Biol Pharm Bull 24:579-581. doi:10.1248/bpb.24.579

Vara Prasad SS, Jeya Kumar SS, Kumar PU, Qadri SS, Vajreswari A (2010) Dietary fatty acid composition alters 11beta-hydroxysteroid dehydrogenase type 1 gene expression in rat retroperitoneal white adipose tissue. Lipids Health Dis 9:111. doi: 10.1186/1476-511X-9-111

Vinayavekhin N, Saghatelian A (2011) Discovery of a proteinmetabolite interaction between unsaturated fatty acids and the nuclear receptor Nur77 using a metabolomics approach. J Am Chem Soc 133:17168-17171. doi:10.1021/Ja208199h

Vinson JA, Teufel K, Wu N (2001) Red wine, dealcoholized red wine, and especially grape juice, inhibit atherosclerosis in a hamster model. Atherosclerosis 156:67-72. doi:10.1016/S0021-9150 (00)00625-0

Xu J, Cho H, O'Malley S, Park JH, Clarke SD (2002) Dietary polyunsaturated fats regulate rat liver sterol regulatory element binding proteins- 1 and -2 in three distinct stages and by different mechanisms. J Nutr 132:3333-3339

Yang ZH, Miyahara H, Takemura S, Hatanaka A (2011) Dietary saury oil reduces hyperglycemia and hyperlipidemia in diabetic KKAy mice and in diet-induced obese C57BL/6 J mice by altering gene expression. Lipids 46:425-434. doi:10.1007/ s11745-011-3553-1

Yokoyama C, Wang X, Briggs MR, Admon A, Wu J, Hua X, Goldstein JL, Brown MS (1993) SREBP-1, a basic-helix-loophelix-leucine zipper protein that controls transcription of the low density lipoprotein receptor gene. Cell 75:187-197. doi:10.1016/ S0092-8674(05)80095-9

Yu-Poth S, Yin D, Kris-Etherton PM, Zhao G, Etherton TD (2005) Long-chain polyunsaturated fatty acids upregulate LDL receptor protein expression in fibroblasts and HepG2 cells. J Nutr 135:2541-2545

Zhang P, Hu Y, Yang J, Zheng L, Wang Q (2012) The orphan nuclear receptor Nur77 regulates hepatic cholesterol metabolism through the suppression of LDLR and HMGCR expression. Mol Med Report 5:1541-1547. doi:10.3892/mmr.2012.850

Zheng X, Rivabene R, Cavallari C, Napolitano M, Avella M, Bravo E, Botham KM (2002) The effects of chylomicron remnants enriched in $n-3$ or $n-6$ polyunsaturated fatty acids on the transcription of genes regulating their uptake and metabolism by the liver: influence of cellular oxidative state. Free Radic Biol Med 32:1123-1131. doi:10.1016/S0891-5849(02)00830-4 